\title{
Effects of hypertonic sodium chloride solution on the electrophysiologic alterations caused by bupivacaine in the dog heart
}

A. Scalabrini,

F. Corregiari and M. Rocha e Silva
Divisão de Pesquisa, Instituto do Coração, Faculdade de Medicina, Universidade de São Paulo, São Paulo, SP, Brasil

\section{Correspondence \\ A. Scalabrini \\ Disciplina de Emergências Clínicas \\ Av. Dr. Enéas C. Aguiar, 255 \\ 5o andar, Sala 5023 \\ 05403-010 São Paulo, SP \\ Brasil \\ E-mail: ascala@uol.com.br}

Research supported by FAPESP and Fundação E.J. Zerbini.

Received February 25, 2002 Accepted August 20, 2002

\begin{abstract}
The effects of various hypertonic solutions on the intraventricular conduction, ventricular repolarization and the arrhythmias caused by the intravenous (iv) injection of bupivacaine $(6.5 \mathrm{mg} / \mathrm{kg})$ were studied in sodium pentobarbital-anesthetized mongrel dogs. Hypertonic solutions, given iv $5 \mathrm{~min}$ before bupivacaine, were $7.5 \%$ (w/v) $\mathrm{NaCl}, 5.4 \%$ $(\mathrm{w} / \mathrm{v}) \mathrm{LiCl}, 50 \%(\mathrm{w} / \mathrm{v})$ glucose $(2,400 \mathrm{mOsm} / \mathrm{l}, 5 \mathrm{ml} / \mathrm{kg})$, or $20 \%$ $(\mathrm{w} / \mathrm{v})$ mannitol $(1,200 \mathrm{mOsm} / \mathrm{l}, 10 \mathrm{ml} / \mathrm{kg})$. Bupivacaine induced severe arrhythmias and ventricular conduction and repolarization disturbances, as reflected by significant increases in QRS complex duration, HV interval, IV interval and monophasic action potential duration, as well as severe hemodynamic impairment. Significant prevention against ventricular electrophysiologic and hemodynamic disturbances and ventricular arrhythmias was observed with $7.5 \% \mathrm{NaCl}$ (percent increase in QRS complex duration: $164.4 \pm 21.8 \%$ in the non-pretreated group vs $74.7 \pm 14.1 \%$ in the pretreated group, $\mathrm{P}<0.05$; percent increase in HV interval: $131.4 \pm 16.1 \%$ in the non-pretreated group $v s$ $58.2 \pm 7.5 \%$ in the pretreated group, $\mathrm{P}<0.05$; percent increase in monophasic action potential duration: $22.7 \pm 6.8 \%$ in the non-pretreated group vs $9.8 \pm 6.3 \%$ in the pretreated group, $\mathrm{P}<0.05$; percent decrease in cardiac index: $-46 \pm 6 \%$ in the non-pretreated group $v s-28$ $\pm 5 \%$ in the pretreated group, $\mathrm{P}<0.05$ ). The other three hypertonic solutions were ineffective. These findings suggest an involvement of sodium ions in the mechanism of hypertonic protection.
\end{abstract}

\section{Introduction}

Local anesthetics are a large group of drugs sharing the same mechanism of action, i.e., blockade of fast $\mathrm{Na}^{+}$channels at the membrane level (1). In the peripheral nerve, this mechanism is responsible for the anesthetic effect, preventing impulse conduction
Key words

- Local anesthetics

- Cardiotoxicity

- Cardiac electrophysiology

- Intraventricular conduction

- Sodium ion

- Hypertonic solutions 
myocardial repolarization, prolonging the recovery time of the fast sodium channel and consequently increasing the refractory period (6-8).

Bupivacaine is a local anesthetic widely used in anesthesiology because of its long duration of action. However, its extremely high affinity for the membrane channels can lead to toxic cardiac electrophysiologic effects when the drug is accidentally administered $i v(4,9-11)$. There are several reports of serious anesthetic accidents and fatalities due to inadvertent $i v$ injection or enhanced absorption of bupivacaine during regional anesthesia (12-15).

Because of the rapid onset and severity of arrhythmias and hypotension, the management of this condition is very difficult. In fact, there is no consensus on how to treat this event (16-20).

Hypertonic sodium solutions effectively correct the hypotension induced by severe hemorrhage $(21,22)$. Prehydration with small amounts of hypertonic saline is also effective to minimize hypotension associated with spinal anesthesia (23). Simonetti et al. (24) studied the effects of hypertonic saline on the hypotension caused by $i v$ bupivacaine and noticed a protective effect on the cardiac arrhythmias as well. This led us to investigate the effects of hypertonic solutions on the electrophysiologic and hemodynamic alterations induced by toxic doses of bupivacaine in dogs.

\section{Material and Methods}

This experiment was conducted according to NIH guidelines for the use of experimental animals and reviewed by the Institutional Board. Seventy-three mongrel dogs of either sex weighing $16.7 \pm 4.7 \mathrm{~kg}$ were anesthetized with $20 \mathrm{mg} / \mathrm{kg} i v$ sodium pentobarbital and ventilated with a Takaoka model 670 volume ventilator with $100 \%$ oxygen. The left femoral artery was cannulated and used for arterial pressure monitoring. The right femoral vein was cannulated for drug infusion and the right femoral artery for blood sampling. A lead II surface electrocardiogram was monitored throughout the experiment.

\section{Studies on intraventricular conduction}

A \#5F bipolar electrode was introduced into the left femoral vein of $57 \mathrm{dogs}$, and positioned by fluoroscopy at the level of the septal leaflet of the tricuspid valve for His bundle electrogram recording. Two other \#5F bipolar electrodes were then introduced into the left jugular vein; one was positioned by fluoroscopy in the upper right atrium to record a right atrial electrogram close to the sinus node, and the other in the right ventricular apex to record the right ventricular electrogram. Recordings were obtained with a Hewlett-Packard model 8890A polygraph at a bandpass of 50 to $500 \mathrm{~Hz}$ and recorded on Kodak Linagraph 2201 photographic paper at a speed of $100 \mathrm{~mm} / \mathrm{s}$. Recorded data were: i) QRS complex duration; ii) HV interval, namely the time interval between the His bundle spike and the first deflection of the ventricular electrogram; iii) IV interval, i.e., the time interval between the ventricular electrograms obtained at the His bundle electrogram site and the right ventricular apex.

The dogs were then assigned to five groups according to the pretreatment they received: B6 (17 dogs) - $i v$ injection of 6.5 $\mathrm{mg} / \mathrm{kg}$ bupivacaine; H5B6 (17 dogs), iv injection of $6.5 \mathrm{mg} / \mathrm{kg}$ bupivacaine $5 \mathrm{~min}$ after pretreatment with $5 \mathrm{ml} / \mathrm{kg} 7.5 \%(\mathrm{w} / \mathrm{v}) \mathrm{NaCl}$; L5B6 (9 dogs), iv injection of $6.5 \mathrm{mg} / \mathrm{kg}$ bupivacaine $5 \mathrm{~min}$ after pretreatment with 5 $\mathrm{ml} / \mathrm{kg}$ 5.4\% (w/v) LiCl; G5B6 (7 dogs), iv injection of $6.5 \mathrm{mg} / \mathrm{kg}$ bupivacaine $5 \mathrm{~min}$ after pretreatment with $5 \mathrm{ml} / \mathrm{kg} 50 \%(\mathrm{w} / \mathrm{v})$ glucose; M10B6 (7 dogs), iv injection of 6.5 $\mathrm{mg} / \mathrm{kg}$ bupivacaine $5 \mathrm{~min}$ after pretreatment with $10 \mathrm{ml} / \mathrm{kg} \mathrm{20 \%}$ (w/v) mannitol.

Recordings were obtained at baseline, 
5 min after pretreatment, immediately after bupivacaine injection, and every $30 \mathrm{~s}$ until death or for $3 \mathrm{~min}$ after the injection.

\section{Studies on ventricular repolarization}

In 16 other dogs, a monophasic action potential electrode was introduced through the right carotid artery and positioned at the level of the left ventricular apex by fluoroscopy. Monophasic action potential recordings were then obtained with a model ES2000 Gould polygraph at a bandpass of 0.5 to 300 $\mathrm{Hz}$ and acquired with a microcomputer using a software developed by the Bioengineering Division of the Heart Institute. The ventricular repolarization was analyzed taking into account the duration (ms) of the monophasic action potential at 20 (T20), 50 (T50) and 90\% (T90) repolarization. The dogs were then assigned to two groups: B6R (8 dogs), same as group B6; H5B6R (8 dogs), same as group H5B6.

Recordings were obtained at the same times as in the intraventricular conduction studies.

\section{Studies on cardiovascular responses and metabolic changes}

In all dogs, mean arterial pressure was monitored throughout the experiment. In 8 dogs of group B6 and 8 dogs of group H5B6, a \#7F Edwards 3-way thermodilution catheter was introduced into the right jugular vein and its tip positioned in the pulmonary circulation to record pulmonary pressures and to measure cardiac output. In these dogs, arterial blood samples for blood bupivacaine levels, plasma $\mathrm{Na}$ and $\mathrm{K}$ levels, plasma osmolarity, and arterial blood gases were drawn at baseline, immediately and $5 \mathrm{~min}$ after $7.5 \% \mathrm{NaCl}$ infusion, and then at 30,90 , and $180 \mathrm{~s}$ after bupivacaine injection. At the same times, cardiac output was measured using a model COM-1 American Edwards Instruments Cardiac Output Computer.

\section{Data analysis}

Intraventricular conduction and pressure measurements were performed using a Digicon model 1812 digitizer table (Alberta, Canada) coupled to a microcomputer with a dedicated software. Each measurement was the mean of five consecutive readings during sinus rhythm. Intraventricular repolarization measurements were performed using a microcomputer with a dedicated software.

Plasma osmolarity was measured with a model 3D2 Advanced Digimatic Osmometer (Needham Heights, MA, USA), with each value representing the mean of two consecutive measurements.

Blood bupivacaine levels were measured by high-performance liquid chromatography.

\begin{tabular}{|c|c|c|c|c|c|c|c|c|c|c|}
\hline & \multicolumn{2}{|c|}{$\mathrm{B} 6(\mathrm{~N}=17)$} & \multicolumn{2}{|c|}{ H5B6 $(\mathrm{N}=17)$} & \multicolumn{2}{|c|}{ L5B6 ( $N=9)$} & \multicolumn{2}{|c|}{ G5B6 $(N=7)$} & \multicolumn{2}{|c|}{ M10B6 $(N=7)$} \\
\hline & Control & After & Control & After & Control & After & Control & After & Control & After \\
\hline $\begin{array}{l}\text { QRS } \\
\text { interval }\end{array}$ & $48.6 \pm 1.6$ & $127.6 \pm 11.6^{*}$ & $59.4 \pm 3.1$ & $101.0 \pm 7.0^{*}$ & $52.2 \pm 3.9$ & $132.6 \pm 14.7^{*}$ & $55.3 \pm 4.6$ & $137.7 \pm 14.4^{*}$ & $48.9 \pm 3.3$ & $125.7 \pm 8.3^{*}$ \\
\hline $\begin{array}{l}\text { HV } \\
\text { interval }\end{array}$ & $21.8 \pm 0.8$ & $49.8 \pm 3.2^{*}$ & $24.5 \pm 1.3$ & $38.6 \pm 2.5^{*}$ & $22.4 \pm 1.1$ & $51.5 \pm 3.0^{*}$ & $23.3 \pm 1.0$ & $59.9 \pm 5.8^{*}$ & $22.3 \pm 1.2$ & $48.0 \pm 3.5^{*}$ \\
\hline $\begin{array}{l}\text { IV } \\
\text { interval }\end{array}$ & $20.9 \pm 1.5$ & $45.4 \pm 3.3$ & $21.5 \pm 42.0$ & $42.0 \pm 2.8$ & $21.0 \pm 0.4$ & $41.0 \pm 5.2$ & $23.6 \pm 2.8$ & $46.1 \pm 3.3$ & $20.3 \pm 1.7$ & $36.7 \pm 3.1$ \\
\hline
\end{tabular}

Data are reported as means \pm SEM in ms. B6: ivinjection of $6.5 \mathrm{mg} / \mathrm{kg}$ bupivacaine; H5B6, L5B6, G5B6, and M10B6: pretreatment with $5 \mathrm{ml} / \mathrm{kg} 7.5 \% \mathrm{NaCl}$ $5 \mathrm{ml} / \mathrm{kg} 5.4 \% \mathrm{LiCl}, 5 \mathrm{ml} / \mathrm{kg} \mathrm{50 \%}$ glucose, and $10 \mathrm{ml} / \mathrm{kg} 20 \%$ mannitol, respectively, followed by iv injection of $6.5 \mathrm{mg} / \mathrm{kg}$ bupivacaine.

${ }^{*} \mathrm{P}<0.05$ compared to respective control (ANOVA). 
Figure 1. Recording from a typical B6 dog. Note the widening of all intervals (QRS, HV and IV) starting immediately after bupivacaine injection, followed by hypotension, ventricular tachycardia and death. LII = ECG lead II; HRA $=$ high right atrial electrogram; $\mathrm{HBE}=$ His bundle electrogram; $\mathrm{RV}=$ right ventricular electrogram; MAP = mean arterial pres sure.

Figure 2. Recording from a typical H5B6 dog. Note the slight widening of all intervals, with maintenance of mean arterial pressure. For abbreviations, see legend to Figure 1.

\section{Statistical analysis}

Results are expressed as mean \pm SEM of maximal percent variation from basal values and the normality of this notation was tested. Statistical analysis was performed by
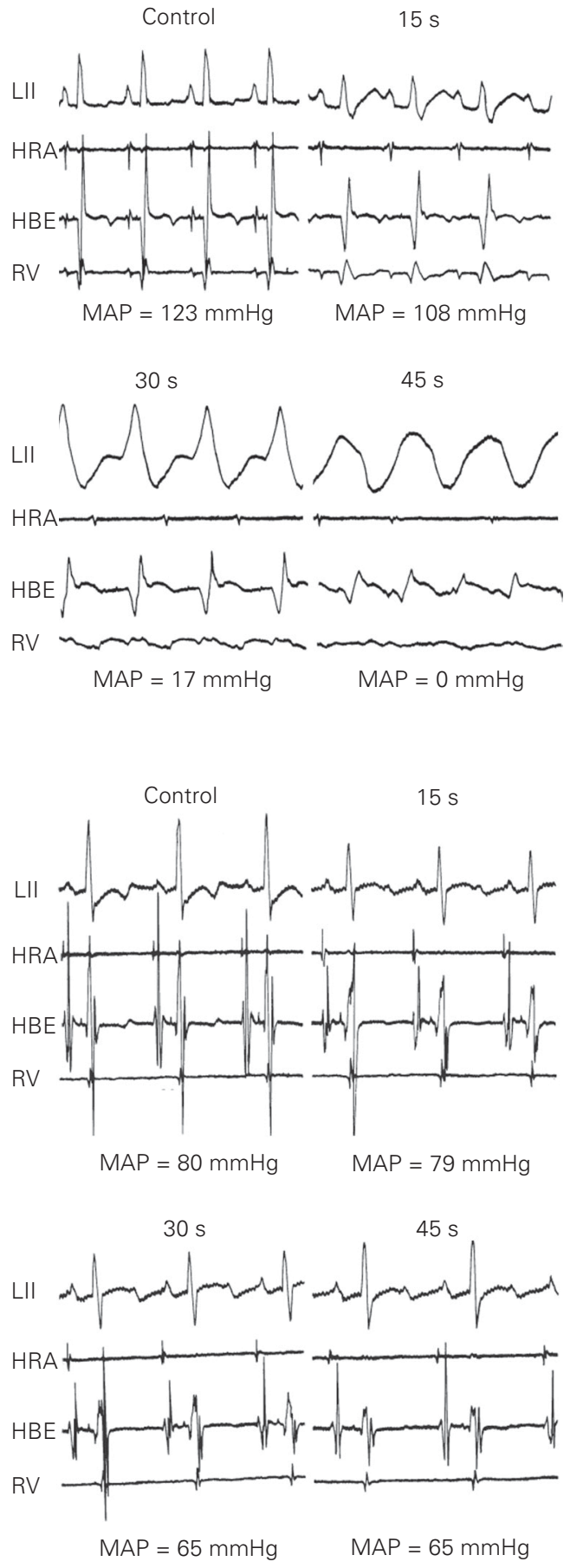

ANOVA or the Student $t$-test for independent samples; if ANOVA showed significant differences, the Student-Newman-Keuls test was applied to determine the differences. The level of significance was set at 0.05 .

\section{Results}

\section{Intraventricular conduction}

Bupivacaine severely prolonged intraventricular conduction times (Table 1). Its effect was immediate, reaching a peak within 30 to $90 \mathrm{~s}$ and decreasing thereafter.

In group B6, QRS complex duration increased by $164.4 \pm 21.8 \%$, HV interval by $131.4 \pm 16.1 \%$ and IV interval by $128.5 \pm$ $18.8 \%$. Among the hypertonic solutions tested, only $7.5 \% \mathrm{NaCl}$ reduced this effect. In group H5B6, the QRS complex duration increased by $74.7 \pm 14.1 \%(\mathrm{P}=0.005)$ and the HV interval by $58.2 \pm 7.5 \%(\mathrm{P}<0.001)$. The IV interval increased by $115.5 \pm 18.8 \%$ $(\mathrm{P}=0.573)$; although this shows a tendency to a lower increase compared to B6, this value was not statistically significant and not different from the other treatments.

The other hypertonic solutions had no effect at all: in group L5B6, QRS complex duration increased by $157.1 \pm 27.2 \%$, HV interval by $134.2 \pm 17.7 \%$ and IV interval by $96.3 \pm 25.8 \%$; in group G5B6, QRS complex increased by $149.1 \pm 14.4 \%$, HV interval by $156.6 \pm 20.7 \%$ and IV interval by $102.3 \pm$ $12.3 \%$, and in group M10B6, QRS complex increased by $164.1 \pm 25.7 \%$, HV interval by $115.6 \pm 10.5 \%$ and IV interval by $81.9 \pm$ $9.7 \%$. None of these increases differed from group B6.

Figures 1 and 2 show the electrophysiologic recordings of typical dogs, one from group B6 and one from group H5B6. Note that changes in QRS duration, $\mathrm{HV}$, and IV intervals in the H5B6 dog are much less marked than in the B6 dog; also note the development of ventricular tachycardia in the B6 dog. 


\section{Ventricular repolarization}

Bupivacaine also affected left ventricular repolarization analyzed by the monophasic action potential (Table 2). The effects on repolarization were also very early, starting immediately after injection of the drug, reaching a peak 30 to $90 \mathrm{~s}$ later and decreasing thereafter.

Bupivacaine shortened T20 (the "plateau" phase), but increased T90 (the total action potential duration). Thus, in group B6R, T20 was shortened by $-25.0 \pm 7.5 \%$ $(\mathrm{P}=0.03), \mathrm{T} 50$ by $-15.5 \pm 6.9 \%(\mathrm{P}=0.15)$ and $\mathrm{T} 90$ increased by $22.7 \pm 6.8 \%(\mathrm{P}=$ 0.003 ) after the injection of bupivacaine. Conversely, in group H5B6R the effects were much less marked: T20 increased by $4.1 \pm$ $16.3 \%(\mathrm{P}=0.91), \mathrm{T} 50$ by $10.4 \pm 6.8 \%(\mathrm{P}=$ $0.236)$ and $\mathrm{T} 90$ by $9.8 \pm 6.3 \%(\mathrm{P}=0.302)$.

Figures 3 and 4 show typical monophasic action potential recordings for one dog in group B6R and another in group H5B6R. Note the differences in the ventricular repolarization alterations, clearly visible in the B6R dog and much less apparent in the H5B6R dog.

\section{Cardiac arrhythmias and mortality}

The arrhythmias observed in this series were sinus node dysfunction (SND) and ventricular arrhythmias (Table 3). SND caused severe bradycardia and, in some dogs, led to death due to asystole. Ventricular arrhythmias were classified as: 1) nonsustained ventricular tachycardia (NSVT), when the episode lasted less than $30 \mathrm{~s} ; 2$ ) sustained ventricular tachycardia (SVT), when it lasted more than $30 \mathrm{~s}$ or degenerated to ventricular fibrillation (VF), and 3) primary VF. Each arrhythmia occurred alone or in combination in each animal.

In the non-NaCl-pretreated groups (B6 and B6R), SND occurred in $2 / 25$ dogs, NSVT in $2 / 25$ dogs, SVT in $5 / 25$ dogs, and VF in $8 / 25$ dogs, and $12 / 25$ dogs died. When $7.5 \%$
Table 2. Maximal variation of the intraventricular repolarization parameters in the groups.

\begin{tabular}{lrrrrr}
\hline & \multicolumn{2}{c}{ B6R } & & \multicolumn{2}{c}{ H5B6R } \\
\cline { 2 - 3 } \cline { 5 - 6 } & \multicolumn{1}{c}{ Control } & After & & Control & After \\
\hline T20 & $59.5 \pm 4.3$ & $44.1 \pm 4.8^{*}$ & & $72.3 \pm 6.4$ & $70.9 \pm 10.9$ \\
T50 & $95.0 \pm 4.2$ & $82.6 \pm 7.0$ & & $11.1 \pm 5.3$ & $123.0 \pm 8.0$ \\
T90 & $125.4 \pm 4.7$ & $155.1 \pm 6.7^{*}$ & & $142.5 \pm 6.4$ & $156.2 \pm 11.1$ \\
\hline
\end{tabular}

Data are reported as means \pm SEM for $\mathrm{N}=8$ in each group. T20, T50, T90: duration (ms) of the monophasic action potential at 20,50 and $90 \%$ repolarization, respectively. $\mathrm{B} 6 \mathrm{R}$ and H5B6R are the same as B6 and H5B6, respectively (see Table 1).

${ }^{*} \mathrm{P}<0.05$ compared to respective control (ANOVA).

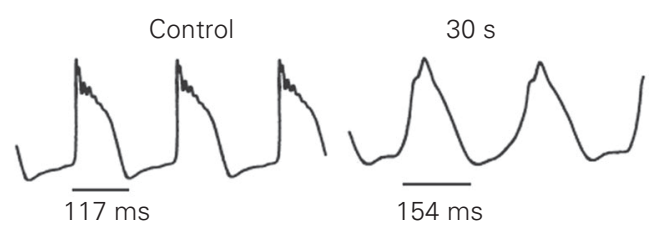

Figure 3. Monophasic action potential recording from a typical B6R dog. Note the typical bupivacaine action: shortening of T20 (the plateau phase) with significant enlargement of T90 (the total duration of the potential).

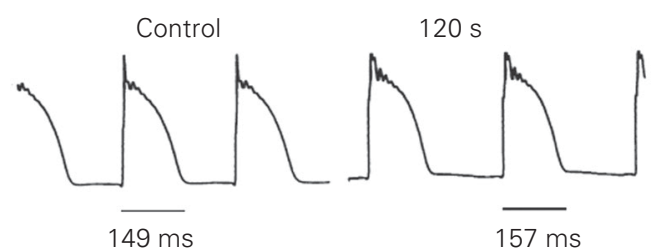

Figure 4. Monophasic action potential recording from a typical H5B6R dog. There was practically no alteration in the potential morphology and duration after bupivacaine injection.

\begin{tabular}{lccccc}
\multicolumn{6}{l}{ Table 3. Cardiac arrhythmias and mortality. } \\
\hline & SND & NSVT & SVT & VF & Death \\
\hline B6 & 2 & 2 & 3 & 3 & 5 \\
H5B6 & 0 & 1 & 0 & 0 & 0 \\
B6R & 0 & 0 & 5 & 5 & 7 \\
H5B6R & 1 & 0 & 1 & 1 & 1 \\
L5B6 & 4 & 3 & 2 & 2 & 3 \\
G5B6 & 6 & 5 & 1 & 1 & 3 \\
M10B6 & 5 & 3 & 1 & 1 & 2
\end{tabular}

SND: sinus node dysfunction; NSVT: nonsustained ventricular tachycardia; SVT: sustained ventricular tachycardia; VF: ventricular fibrillation. For group abbreviations, see legends to Tables 1 and 2 . 
$\mathrm{NaCl}$ was used as pretreatment (groups $\mathrm{H} 5 \mathrm{~B} 6$ and H5B6R), only one dog showed one episode of NSVT, one dog presented SND and another dog VF. The overall mortality was 1/25 dogs. Pretreatment with the other hypertonic solutions (groups L5B6, G5B6 and M10B6) had no protective effect, as shown in Table 3.

\section{Cardiovascular responses and metabolic changes (Table 4)}

Cardiac dynamics changed substantially after bupivacaine injection, with marked depression in cardiac function parameters. Thus, in group B6, mean arterial pressure decreased from $110.0 \pm 3.4$ to $40.8 \pm 5.5$ $\mathrm{mmHg}(-62 \pm 5 \%)$, cardiac index decreased from $3.0 \pm 0.2$ to $1.7 \pm 0.21 \mathrm{~min}^{-1} \mathrm{~m}^{-2}(-46 \pm$ $6 \%$ ), systolic pulmonary pressure increased from $10.1 \pm 0.9$ to $13.6 \pm 1.0 \mathrm{mmHg}(38 \pm$ $9 \%$ ), diastolic pulmonary pressure from 6.5

\begin{tabular}{|c|c|c|c|c|}
\hline & \multicolumn{2}{|c|}{ B6 } & \multicolumn{2}{|c|}{ H5B6 } \\
\hline & Control & After & Control & After \\
\hline $\mathrm{MAP}(\mathrm{mmHg})$ & $110.0 \pm 3.4$ & $40.8 \pm 5.5^{*}$ & $116.3 \pm 7.3$ & $82.5 \pm 6.5^{*}$ \\
\hline $\mathrm{Cl}\left(I \mathrm{~min}^{-1} \mathrm{~m}^{-2}\right)$ & $3.0 \pm 0.2$ & $1.7 \pm 0.2$ & $3.1 \pm 0.3$ & $2.3 \pm 0.3$ \\
\hline $\operatorname{SPP}(\mathrm{mmHg})$ & $10.1 \pm 0.9$ & $13.6 \pm 1.0$ & $12.9 \pm 1.1$ & $23.8 \pm 2.5^{*}$ \\
\hline $\mathrm{DPP}(\mathrm{mmHg})$ & $6.5 \pm 0.9$ & $9.8 \pm 1.0$ & $8.2 \pm 0.9$ & $17 \pm 1.8^{*}$ \\
\hline $\mathrm{Na}(\mathrm{mEq} / \mathrm{l})$ & $140.3 \pm 1.3$ & $139.5 \pm 1.6$ & $141.6 \pm 2.0$ & $161.6 \pm 5.7^{*}$ \\
\hline $\mathrm{K}(\mathrm{mEq} / \mathrm{l})$ & $3.5 \pm 0.1$ & $3.2 \pm 0.1$ & $3.7 \pm 0.1$ & $2.9 \pm 0.2^{*}$ \\
\hline Osmolarity (mOsm/l) & $280 \pm 2$ & $287 \pm 3$ & $282 \pm 3$ & $325 \pm 10^{*}$ \\
\hline Bupivacaine $(\mu \mathrm{g} / \mathrm{ml})$ & 0 & $15 \pm 2$ & 0 & $20 \pm 4$ \\
\hline $\mathrm{pH}$ & $7.4 \pm 0.02$ & $7.41 \pm 0.02$ & $7.36 \pm 0.01$ & $7.35 \pm 0.02$ \\
\hline $\mathrm{pCO}_{2}$ & $34 \pm 2$ & $30 \pm 2$ & $36 \pm 1$ & $34 \pm 1$ \\
\hline $\mathrm{pO}_{2}$ & $292 \pm 16$ & $293 \pm 9$ & $281 \pm 13$ & $269 \pm 18$ \\
\hline Bic & $21 \pm 1$ & $20 \pm 1$ & $20 \pm 1$ & $18 \pm 0$ \\
\hline
\end{tabular}

MAP: mean arterial pressure; Cl: cardiac index; SPP: systolic pulmonary pressure; DPP: diastolic pulmonary pressure; Bic: bicarbonate. For group abbreviations, see legend to Table 1. ${ }^{*} \mathrm{P}<0.05$ compared to respective control (ANOVA). \pm 0.9 to $9.8 \pm 1.0 \mathrm{mmHg}(63 \pm 20 \%)$, and mean pulmonary pressure from $8.4 \pm 0.9$ to $12.1 \pm 0.9 \mathrm{mmHg}(49 \pm 11 \%)$.

Pretreatment with $7.5 \% \mathrm{NaCl}$ significantly decreased these actions: mean arterial pressure was reduced only from $116.3 \pm 7.3$ to $82.5 \pm 6.5 \mathrm{mmHg}(-26 \pm 6 \%, \mathrm{P}<0.001)$, cardiac index from $3.1 \pm 0.3$ to $2.3 \pm 0.31$ $\min ^{-1} \mathrm{~m}^{-2}(-28 \pm 5 \%, \mathrm{P}=0.04)$, systolic pulmonary pressure increased from $12.9 \pm$ 1.1 to $23.8 \pm 2.5 \mathrm{mmHg}(85 \pm 13 \%, \mathrm{P}=$ 0.01 ), diastolic pulmonary pressure from 8.2 \pm 0.9 to $17.0 \pm 1.8 \mathrm{mmHg}(113 \pm 16 \%, \mathrm{P}=$ 0.07 ), and mean pulmonary pressure from $10.8 \pm 1.0$ to $21.6 \pm 2.4 \mathrm{mmHg}(100 \pm 15 \%$, $\mathrm{P}=0.02)$. The significant increases in pulmonary pressures in group H5B6 did not lead to clinical pulmonary congestion.

Plasma osmolarity was significantly higher following hypertonic $\mathrm{NaCl}$ treatment. Plasma osmolarity increased from $280 \pm 2$ to $287 \pm 3 \mathrm{mOsm} / \mathrm{l}(3 \pm 1 \%)$ in group B6 and from $282 \pm 3$ to $325 \pm 10 \mathrm{mOsm} / 1(15 \pm 5 \%$, $\mathrm{P}=0.02$ ) in group H5B6.

Plasma sodium levels decreased from $140.3 \pm 1.3$ to $139.5 \pm 1.6 \mathrm{mEq} / 1(-1 \pm 1 \%)$ in group B6, but increased from $141.6 \pm 2.0$ to $161.6 \pm 5.7 \mathrm{mEq} / 1$ in group H5B6 $(14 \pm 2 \%$, $\mathrm{P}<0.001)$. Plasma potassium levels decreased from $3.5 \pm 0.1$ to $3.2 \pm 0.1 \mathrm{mEq} / 1(-7 \pm 1 \%)$ in group B6 and from $3.7 \pm 0.1$ to $2.9 \pm 0.2$ $\mathrm{mEq} / \mathrm{l}(-24 \pm 4 \%, \mathrm{P}=0.001)$ in group H5B6.

Blood bupivacaine levels similarly reached toxic levels in groups B6 and H5B6. In group B6, the maximal levels were $15 \pm 2$ $\mu \mathrm{g} / \mathrm{ml} 30 \mathrm{~s}$ after bupivacaine injection, decreasing to $5 \pm 1 \mu \mathrm{g} / \mathrm{ml} 180 \mathrm{~s}$ after the injection; in group H5B6, the levels were comparable: the maximal levels were $20 \pm 4$ $\mu \mathrm{g} / \mathrm{ml}$, decreasing to $10 \pm 2 \mu \mathrm{g} / \mathrm{ml}$, measured at the same times.

The other metabolic parameters for groups B6 and H5B6 did not change significantly.

The mean arterial pressure for group L5B6 changed from $121.6 \pm 7.3$ to $61.8 \pm 10.0$ $\mathrm{mmHg}$, group G5B6 from $127.9 \pm 6.7$ to $74.3 \pm 9.7 \mathrm{mmHg}$ and group M10B6 
from $116.4 \pm 9.2$ to $71.1 \pm 10.6 \mathrm{mmHg}$.

\section{Discussion}

The main finding of our study was that hypertonic $\mathrm{NaCl}$ pretreatment effectively protected against the electrophysiologic disturbances and ventricular arrhythmias induced by bupivacaine intoxication. Toxic blood levels of bupivacaine, above $5 \mu \mathrm{g} / \mathrm{ml}$ (1), were detected in every dog in this study.

It is well known that bupivacaine binds to the inactivated $\mathrm{Na}^{+}$channel, slows phase 0 of the action potential and impairs stimulus conduction in the heart. This was well demonstrated in our study: QRS complex duration, HV interval and IV interval consistently increased in all dogs. The fact that this anesthetic binds to the $\mathrm{Na}^{+}$channel in the inactivated state or during the plateau phase, plus a calcium channel blocking effect (25), may explain the shortening of T20 observed in our data. It has been shown that bupivacaine blocks delayed rectifier (8) and transient outward $\mathrm{K}^{+}$currents (7), and prolongs action potential duration, as seen in our material by the prolongation of the monophasic action potential in T90.

Among the hypertonic solutions tested, only $7.5 \% \mathrm{NaCl}$ prevented the electrophysiologic effects of the drug both on stimulus conduction and ventricular repolarization. Hyperosmolarity per se cannot explain this protection. The effects of hyperosmolarity on normal electrophysiologic parameters have been studied by other authors. Ehara and Hasegawa (26), using isolated guinea pig ventricular muscle submitted to hypertonic electrolytic and non-electrolytic solutions, found increases in action potential duration and a decrease in Vmax during phase 0 when a non-electrolytic solution (glucose or sucrose) was used. The same investigators also tested lithium chloride and found an initial increase in Vmax. However, this action only lasted for a short period of time.
Our findings are consistent with these data. Actually, from the studies mentioned above, it would be expected that hypertonic solutions other than $\mathrm{Na}^{+}$salts might worsen the electrophysiologic disturbances since their effects tend to decrease phase 0 (and consequently the conduction velocity) and to prolong the action potential duration. This is suggestive of what we found when glucose and mannitol were used: no improvement or even a slight impairment in intraventricular conduction was observed when compared to the non-pretreated group. The results after $\mathrm{LiCl}$ infusion, however, were not what might have been expected: a slight protection might have occurred, but our data showed results similar to those obtained when non-electrolytic solutions were tested.

The mechanism of the protective effect of sodium is unknown. There is evidence that sodium overload by itself has no effect on normal myocardial electrophysiology (2729). Thus, it probably reverses, at least in part, the bupivacaine sodium channel blockade. Our results differ from those obtained with lidocaine, which showed no protective effect with hypertonic saline $(30,31)$. Both drugs bind to the sodium channel during the inactivated state; however, different binding sites or properties may prevent competition between extracellular sodium and lidocaine but not bupivacaine. The bupivacaine used in this study is an equimolar mixture of $\mathrm{R}(+)$ and S(-)-bupivacaine (levobupivacaine). Levobupivacaine has been reported to be less arrhythmogenic than bupivacaine (32, 33). Levobupivacaine had less affinity for myocardial sodium channels than dextrobupivacaine and dissociation from sodium channels was faster $(34,35)$. Thus, further studies are needed to determine whether sodium overload has different protective effects on the electrophysiologic alterations induced by bupivacaine and levobupivacaine.

Hemodynamic and metabolic changes cannot explain the protection. No metabolic differences were found between groups, ex- 
cept for plasma sodium levels. Hemodynamic findings give little insight into electrophysiologic mechanisms, although $\mathrm{NaCl}$-pretreated dogs have a much better hemodynamic outcome; we believe this better outcome is simply part of the action of hypertonic $\mathrm{NaCl}$.

Differences in the effect of hypertonic $\mathrm{NaCl}$ on $\mathrm{HV}$ and IV intervals may suggest that protection occurs mainly in the proximal part of the conduction system (HV interval). However, the limitations of the IV interval as a measure of peripheral conduction must be considered. It must be remembered that several structures (right bundle branch, Purkinje network, and right ventricular muscle), with different electrophysiologic properties, compose the IV interval.

In conclusion, pretreatment with hypertonic $\mathrm{NaCl}$ effectively protects against the cardiovascular toxicity of bupivacaine, an effect not seemingly related to hypertonicity alone. Further studies disclosing the mechanisms of such protection should provide insights into the significance and applicability of these findings.

\section{References}

1. Covino BG \& Vassallo HG (1986). Local Anesthetics: Mechanisms of Actions and Clinical Use. Grunne \& Stratton, Inc., New York, NY, USA, 29-55.

2. Vaugham-Williams EM (1984). A classification of antiarrhythmic actions reassessed after a decade of new drugs. Journal of Clinical Pharmacology, 24: 129-147.

3. Campbell TJ (1983). Kinetics of onset of rate-dependent effects of class I antiarrhythmic drugs are important in determining their effects on refractoriness in guinea-pig ventricle, and provide a theoretical basis for their subclassification. Cardiovascular Research, 17: 334-352.

4. Clarkson CW \& Hodeghem LM (1995). Mechanism for bupivacaine depression of cardiac conduction: fast block of sodium channels during the action potential with slow recovery from block during diastole. Anesthesiology, 62: 396-405.

5. Anderson KP, Walker R, Lux RL, Ershler PR, Menlove R, Williams MR, Krall R \& Moddrelle D (1990). Conduction velocity depression and drug-induced ventricular tachyarrhythmias. Circulation, 81: 10241038.

6. Kasten GW (1986). Amide local anesthetic alterations of effective refractory period temporal dispersion: relationship to ventricular arrhythmias. Anesthesiology, 65: 61-66.

7. Castle NA (1990). Bupivacaine inhibits the transient outward $\mathrm{K}$ current but not the inward rectifier in rat ventricular myocytes. Journal of Pharmacology and Experimental Therapeutics, 255: 1038-1064.

8. Courtney KR \& Kendig JJ (1988). Bupivacaine is an effective potassium channel blocker in heart. Biochimica et Biophysica Acta, 939: 163-166.

9. Boettner RB, Dunbar RW, Haley JV \& Morrow DH (1972). A comparison of the antiarrhythmic effects of bupivacaine and lidocaine. Southern Medical Journal, 65: 1328-1330.

10. Chapin JC, Kushins LG, Munson ES \& Schick LM (1980). Lidocaine, bupivacaine, etidocaine and epinephrine-induced arrhythmias during halothane anesthesia in dogs. Anesthesiology, 52: 23-25.

11. Dunbar RW, Boettner RB, Glatz RN, Pennington RE \& Morrow DH (1970). The effect of mepivacaine, bupivacaine and lidocaine on digitalis-induced ventricular arrhythmias. Anesthesia and Analgesia, 49: 761-766.

12. Romanoff ME \& Ellis Jr JS (1991). Bupivacaine toxicity after stellate ganglion block. Anesthesia and Analgesia, 72: 546-548.

13. Gibson P \& Murrell D (1991). Complications of epidural analgesia. Anaesthesia and Intensive Care, 19: 282-284.

14. Salemi S \& Gristina E (1991). Toxic effects of bupivacaine on heart conduction during peridural anesthesia. Minerva Anestesiologica, 57: 468-469.

15. Wolff AP, Hasenbos MA, Liem TH \& Gielen MJ (1992). Accidental overdose of epidural bupivacaine and sufentanil. Regional Anesthesia, 17: 237-238.

16. Kinney WW, Kambam JR \& Wright W (1991). Propranolol pretreatment reduces cardiorespiratory toxicity due to plain, but not epinephrine-containing, intravenous bupivacaine in rats. Canadian Journal of Anaesthesia, 38: 533-536.

17. Bernards CM \& Artu AA (1991). Hexa- methonium and midazolam terminate dysrhythmias and hypertension caused by intracerebroventricular bupivacaine in rabbits. Anesthesiology, 74: 89-96.

18. Hyman SA, Kinney WW, Horn JL, Skelley CC \& Kambam JR (1992). Nimodipine reduces the toxicity of intravenous bupivacaine in rats. Anesthesia and Analgesia, 74: 851-855.

19. De Kock M, Le Polain B, Henin D, Vandewalle F \& Scholtes JL (1993). Clonidine pretreatment reduces the systemic toxicity of intravenous bupivacaine in rats. Anesthesiology, 79: 282-289.

20. Fujita $S$, Endoh $S$, Yasukawa $T$ \& Sari $A$ (1998). Lidocaine increases the ventricular fibrillation threshold during bupivacaine induced cardiotoxicity in pigs. British Journal of Anaesthesia, 80: 218-222.

21. Rocha e Silva M, Velasco IT, Nogueira da Silva RI, Oliveira MA, Negraes GA \& Oliveira MA (1987). Hyperosmotic sodium salts reverse severe hemorrhagic shock: other solutes do not. American Journal of Physiology, 253: H751-H762.

22. Velasco IT, Pontieri V, Rocha e Silva M \& Lopes OU (1980). Hyperosmotic $\mathrm{NaCl}$ and severe hemorrhagic shock. American Journal of Physiology, 239: H664-H673.

23. Wang BW, Chiou YH, Chen WB, Peng TY \& Leung HK (1997). Intravenous pretreatment of hypertonic saline can prevent systemic hypotension induced by spinal anesthesia. Acta Anaesthesiologica Sinica, 35: 85-90.

24. Simonetti MPB, Cremonesi E \& Rodrigues IJ (1987). Influência do $\mathrm{NaCl}$ a 7,5\% (2400 mOsm) nos efeitos cardiocirculatórios da bupivacaina em cães anestesiados. 
Revista Brasileira de Anestesiologia, 37 (Suppl 7): 88 (Abstract).

25. Lynch C (1986). Depression of myocardial contractility in vitro by bupivacaine. Anesthesia and Analgesia, 65: 551-559.

26. Ehara T \& Hasegawa JI (1983). Effects of hypertonic solution on action potential and input resistance in the guinea-pig ventricular muscle. Japanese Journal of Physiology, 33: 151-167.

27. Turgeon J, Wisialowski T, Wong W, Altemeier W, Wikswo J \& Roden D (1992). Suppression of longitudinal versus transverse conduction by sodium channel block. Circulation, 85: 221-226.

28. Bajaj A, Woosley R \& Roden D (1989). Acute electrophysiologic effects of sodium administration in dogs treated with $\alpha$-desmethyl encainide. Circulation, 80: 994-1002.

29. Pentel PR, Fifield J \& Salermo DM (1990).
Lack of effect of hypertonic sodium bicarbonate on QRS duration in patients taking therapeutic doses of class IC antiarrhythmic drugs. Journal of Clinical Pharmacology, 30: 789-794.

30. Barber M, Wendt D, Starmer C \& Grant A (1992). Blockade of cardiac sodium channels: competition between the permeant ion and antiarrhythmic drugs. Journal of Clinical Investigation, 90: 368-381.

31. Ujhelyi MR, Schur M, Frede T, Bottorff MB, Gabel M \& Markel ML (1997). Hypertonic saline does not reverse the sodium channel blocking actions of lidocaine: evidence from electrophysiologic and defibrillation studies. Journal of Cardiovascular Pharmacology, 29: 61-68.

32. Huang YF, Pryor ME, Mather LE \& Veering BT (1998). Cardiovascular and central nervous system effects of intravenous levobupivacaine and bupivacaine in sheep. Anesthesia and Analgesia, 86: 797-804.

33. Gristwood R, Bardsley H, Baker H, Watson N \& Nimmo W (1994). Reduced cardiotoxicity of levobupivacaine compared with racemic bupivacaine (Marcaine): new clinical evidence. Expert Opinion on Investigational Drugs, 3: 1209-1212.

34. Valenzuela C, Synders DJ, Bennett PB, Tamango J \& Hondeghem LM (1995). Stereoselective block of cardiac sodium channels by bupivacaine in guinea pig ventricular myocytes. Circulation, 92: 30143024.

35. Vanhoutte F, Vereecke J, Verbeke N \& Carmeliet E (1991). Stereoselective effects of the enantiomers of bupivacaine on the electrophysiological properties of the guinea pig papillary muscle. British Journal of Pharmacology, 103: 1275-1281. 